Article

\title{
Digital Tools to Foster Inclusiveness: Porto's System of Accessible Itineraries
}

\author{
Miguel Lopes*(D) and Fernando Alves
}

check for updates

Citation: Lopes, M.; Alves, F. Digital Tools to Foster Inclusiveness: Porto's System of Accessible Itineraries. Sustainability 2021, 13, 5840. https:// doi.org/10.3390/su13115840

\section{Academic Editors:}

Carmela Cucuzzella and Marc A. Rosen

Received: 31 March 2021

Accepted: 20 May 2021

Published: 22 May 2021

Publisher's Note: MDPI stays neutral with regard to jurisdictional claims in published maps and institutional affiliations.

Copyright: (c) 2021 by the authors. Licensee MDPI, Basel, Switzerland. This article is an open access article distributed under the terms and conditions of the Creative Commons Attribution (CC BY) license (https:// creativecommons.org/licenses/by/ $4.0 /)$.
CITTA-Research Centre for Territory, Transports and Environment, Faculty of Engineering, University of Porto, 4200-465 Porto, Portugal; alves@fe.up.pt

* Correspondence: mnlopes@fe.up.pt

\begin{abstract}
The recognition, by public authorities, of the shared nature of urban places and the extent and variety of disabling conditions associated with the emergence of phenomena of social exclusion and a steadily ageing population has motivated the creation of new legislation and strategic tools under the umbrella of inclusive design and accessibility for all. This study aims to show how the use of a new interactive accessibility instrument—-the System of Accessible Itineraries (SIA)—can help decision-makers, municipality services and citizens to develop pedestrian-friendly networks in their cities. An in loco analysis of the main features, weaknesses, and potential of public spaces was undertaken within a selected survey area in the city of Porto, with the aim of improving the inclusiveness of public spaces. The integration of several concerns and regulations, pertaining to inclusiveness in the design of public spaces, into an easy-to-understand summary specific to this territory constitutes an important first step towards changing the existing paradigm. Apart from the inherent advantages to citizens with reduced mobility, the SIA also has the ability to inform urban planners concerning areas in need of intervention, prioritizing the execution of corrective actions within the public space. Additionally, due to the morphological similarity of the consolidated urban fabric of most Portuguese and European cities, the adopted interactive framework also reveals a considerable potential for comprehensive replication in many city centres, reducing the physical barriers, in a more integrative land strategy.
\end{abstract}

Keywords: accessibility planning; interactive digital tool; inclusive urban design; public space

\section{Introduction}

Ideally, the urban environment should provide a democratic setting for human presence by increasing the range of available decisions [1-5]. While social equity concerns remain in the foreground of strategies seeking to improve the accessibility conditions of urban centres, cities still fail to reach some citizens. In general, three main components can be identified within the urban accessibility chain: the person, the vehicle, and the built environment [6]. Regarding the "person", planners can do little to counter personal barriers, which depend on medical evaluations and the mindset of the person themselves, [7], while the "vehicle" is the responsibility of the transport operator. However, the "built environment" falls within the domain of the urban planner.

Issues such as the absence or degradation of sidewalks, the lack of accessible pedestrian crossings, or the presence of obstacles emphasize the constant degradation of urban environment quality [8]. Against this background, cities fail to answer the real physical, information and communication needs of their populations. Often, the existence of several small scale (micro) deficiencies of the built environment hinder the implementation of actions designed at the strategic (macro) level [9]. Thus, it urges planning for the elimination of such barriers and the improvement of human movement, with proper conditions of comfort and safety.

The key issue is accessibility. Generally, it involves the recognition, acceptance and promotion of basic human rights at the highest level of health, comfort, safety, and envi- 
ronmental protection [10-13]. In this sense, a planning approach based on accessibility initiatives ensures the legitimacy of land use and urban management instruments $[14,15]$ by changing the focus towards those who are actually meant to enjoy their benefits.

Urban planning is currently facing new challenges, accessibility-wise, with the emergence of a (new) resilient accessibility paradigm. Greater public space inclusiveness and accessibility for all must be ensured, as well as more resilient spaces regarding the adverse effects of climate change and uncertainty (e.g., the pandemic, environment risks). Additionally, while regulations and public space design manuals have attempted to fill this gap, there is still room for innovation. New techniques of evaluation of built environment conditions are fundamental to better inform decision makers, municipality services, and citizens and, consequently, to improve the accessibility of public spaces. In the context of this problem, in 2013, the city of Porto, Portugal, created a strategic tool: the System of Accessible Itineraries (SIA). This new interactive accessibility instrument visions an urban network accessible to any citizen, ensuring inclusiveness regardless of the citizen's physical condition. The SIA was chosen as a case study for this work.

\section{The Birth of Planning for Accessibility}

Considering that pedestrians, through their senses, learn about much of the surrounding environment first-hand, urban form should ideally attach great importance to the act of walking [16,17]. The traditional walkable city, created circa 10,000 years ago, still exists today and is characterized by high densities and land use variety, based on a framework of human scale streets arranged in an organic pattern, of which many examples remain in the historical centres of old European cities [18]. Handy [16] explored the individual motivations and limitations that define the decision to walk. These have been identified as being primarily related to covered distance and time and, in a secondary role, to elements related to urban environmental quality. Agrawal et al. [19] suggested, in this regard, that urban planners, and others involved in city creation, should promote the establishment of direct routes for easy access to main urban functions.

However, in a society where "time is money", this search for faster and more efficient travel masked the growing tyranny of mobility [20], killing the walkable city. Despite efforts towards the implementation of pedestrian arteries and the development of charters and guidelines for increasing the walkability of cities [17,21,22], pedestrian networks have been relegated to the bottom of planning authorities' priorities $[23,24]$. Physical accessibility, comfort and safety were often ignored in the urban development process.

The academic community soon turned to this issue and concepts such as "environmental pressure" [25], "architectural disability" [26] or "apartheid of the design" [27] were created to describe the impact of the physical characteristics of urban space on the population and everyday living, namely, the design and the layout of buildings and places. It has also been argued that small changes can add therapeutic value to an urban space [28], greatly improving its performance, particularly for vulnerable groups such as older people and physically disabled citizens.

However, much of this target population lack the necessary economic resources, or political leverage, to create effective demand for accessible environments and generate debate in relation to this goal $[29,30]$. In addition, the process of city growth has been characterized as a struggle between property developers and investors to extract the highest possible financial benefit [15], blocking the implementation of inclusive environments.

Concepts such as "universal design", "inclusive design" or "design for all" [13,15,28,31] were devised to defend the creation of environments and products that are usable by all without the need for adaptation or specialized solutions. Some concepts went beyond solely physical aspects, as in Burtons and Mitchell's [32] "streets for life". According to this idea, local community residents are encouraged to establish familiar bonds with their surrounding public space. This relationship will help improve residents' well-being and the desire to age in place. 
Accessibility is, then, an essential attribute of sustainable, people-centred built environments, with transversal implementation regarding standards and regulatory binding norms. This interpretation of accessibility is derived from interactions of the characteristics of transportation (e.g., travel speed) and land use systems (e.g., functional densities and mixes), directly related to economic, social and environmental goals [33]. However, critics argue that it is often impossible to provide a "one size fits all" solution, inevitably leading to the exclusion of certain population groups [28]. The application of this concept in the urban context is therefore a task of great complexity, requiring a reflection on the intricacies of the planning process.

Originally, planning, was no more than the application of a scientific process (indicators, parameters and solutions) for the drafting of policies [34]. Plans, as the preferred planning instrument, doubled as documents to support urban management, as well as the chief means of transmitting ideas and proposals. Their inefficiency, however, started being questioned in the early 1980s, with confidence and arrogance being replaced by uncertainty and introspection. The perceived failure of technocratic problem-solving approaches followed the growth of post-positivism. It saw planners as fallible advisors, akin to any other human, operating in a world without universal answers [35-37]. A new rational and insightful method was required in the face of a growing amount of information, views and opinions.

This strong need to combine social, political and disciplinary views has turned planning into more than the sum of elaborate plans $[37,38]$, rather directing it towards the design of solutions tailored to the specificities of each challenge.

Accessibility was not exempt from this process. The first legislation on accessibility was born in the late 1950s, in the United States [39], providing guidelines for the design and construction of new buildings. This later evolved to include standards for public space design. In Europe, up until the early 21st century, policy on accessibility issues was scattered across multiple thematic resolutions, lacking a coherent focus on urban design. Only in 2001 was the realm of physical accessibility integrated into the regulatory framework [40]. This marked the beginning of a new integrated view on the accessibility issues, combining social policy, information and communication, the transport system and the physical aspects of space and building design.

In Portugal, in 1997, the first legislation devoted to technical standards for accessibility, for all buildings and public spaces, was approved [41]. However, due to its weak scheme of penalties, it was not seen as mandatory but rather as a set of intentions. Consequently, it fuelled the underestimation of accessibility issues and the perpetuation of inaccessible urban space. This inertia was fuelled by the clash of different technical interpretations by different divisions of the same municipality. It took until 2006 for new legislation to devise a more severe system of penalties for non-compliance. Soon after, in 2007, a National Accessibility Promotion Plan was launched [42], featuring, for a ten year time frame, an ambitious set of goals:

- Ensure a network of accessible routes connecting the main urban facilities, in a direct link with the 2006 legislation;

- Ensure the full accessibility of new buildings and those subject to requalification actions;

- Support the implementation of context-aware interventions in public spaces in sensible areas (as is the case of historic centres);

- Allow full physical accessibility to electronic urban furniture elements, such as ATM, public payphones and internet access spaces;

- Guarantee the accessibility to public buildings and to those that serve a public function;

To achieve this change in paradigm in accessibility planning in Portugal, this piece of legislation stated the need to detail methodologies and criteria to the evaluation of accessibility conditions, but also the necessary corrective measures. These efforts targeted municipalities, who should devise their own accessibility promotion plans. 


\section{Overcoming the Challenges of Planning for Accessibility}

It became apparent that one of the handicaps of the accessibility of the urban environment was the focus on physical design aspects. From the existing research on the evaluation of public urban spaces, numerous approaches to walking conditions have emerged. Nevertheless, the approaches that tend to link the physical attributes of public spaces to the variables of the built environment have led to a static assessment of a given territory. Other studies have integrated existing good practice rules of urban design into interactive route calculation tools [43-45]. However, all these approaches were limited to a laboratorial setting, lacking the final step in making a positive contribution to society. This lacklustre outcome on a theme that had been gaining traction not only in the scientific literature but also in a regulatory framework appeared to be counterintuitive. However, this can be easily explained by the complexity that is inherent to the urban planning process.

Cities are the product of time, with their different sections being testaments to different eras of urban design, architecture trends, and political and planning concerns [46-48]. Such heterogeneity naturally results in varied accessibility conditions and their corresponding improvement efforts. In some urban contexts, particularly those subject to heritage classification, additional challenges to balance authenticity and conservation add to this complex equation $[49,50]$.

Due to the vast expanse of public spaces, combined with the limited financial means of public authorities, first and foremost, a definition of a hierarchy of interventions was required. In line with the values of a democratic society, any strategy should factor in public buildings and facilities, but also locations that are used by large amounts of visitors. It is also necessary to account for building density and concentration of existing services, as well as their connections to various interest points of the urban structure, by defining legible and coherent links [17]. This notion of a network is essential to avoid isolated spatial interventions, which would undoubtedly reduce its effectiveness. Even though many urban agglomerations have human scale features that limit most travel needs to short distances [18], other larger urban area trips can be more extensive. The limitations of certain vulnerable, physically disabled, and older groups of the population [6] make the dependence solely on pedestrian travel unfeasible. Public transport stands out, then, as a complement to citizen mobility and as an enabler of social inclusion, but only if universal access is guaranteed [15].

In the "accessibility for all" planning process, social cohesion must also constitute an integral part of these plans. Based on the premise that a public space is a product of social construction, which affects practices and social perceptions, notions such as the "right to the city" [51-53] and "just city" [54] have reinforced not only the importance of citizens" individual needs, but also any existing conflicts. Community participation in planning will allow a better definition of users' wants and needs, and thus the implementation of transversal policies and effective measures [10,38,55], together with co-creative space design [56-60]. The consequences of this democratic dimension of accessibility planning are, however, difficult to analyse. This is due not only to the particularities of the different groups of users of spaces, but also to the recognition of the user as an individual player. Foth [59] refers to the complexity of processes that decentralize humans in the design of collaborative cities. An urbanite can be a multiple player-e.g., resident, consumer of services, community consultation participant, co-creator in collaborative approaches, and part of a much larger and more complex ecosystem of more-than-human and cohabitation dimensions.

In line with the idea of city as a system of interconnected parts [38], the capacity for adaptation should also be a key factor when designing a new accessibility-led instrument. Regulations, technological solutions, and materials are prone to evolution, and as such, plans themselves should be permeable to change in order to maintain its effectiveness [37]. In fact, gathering as many relevant data, interpretations, and action formulations as possible during the decision-making process is the best strategy for creating a resilient system facing a range of available options. It should also be noted that technological innovations can 
sometimes lead to cost savings as they introduce solutions optimized to the identified problems [61], whether in data collection, communication strategies, or monitoring. To properly tackle the development of a new accessibility-led instrument, efforts should therefore focus on three axes: urban, social, and operational ones.

\section{The System of Accessible Itineraries-SIA}

Porto, located at the centre of Portugal's second largest metropolitan area, has been experiencing a demographic exodus for several decades. Younger residents and their newly established families moved to the growing suburbs, emptying the core of the metropolitan area. In addition, a steady gentrification process has fostered social asymmetries, with older people as one of the most impacted groups [62,63]. In the latest Portuguese census of 2011, the population pyramid of Porto was clearly indicative of this trend, with nearly $12 \%$ of its residents being aged 75 or above [64]. The mobility impairments of older residents, often compared to those with disabilities $[65,66]$, further reinforced the need for a comprehensive accessibility targeted intervention.

Following the regulatory framework, the municipality of Porto, following a nationwide trend, implemented an accessibility intervention plan in the year of 2006. However, this plan focused only on a small fraction of the downtown area, whose obstacles and barriers were already few, thus downplaying the potential of a plan of this nature. This strict implementation of regulatory principles to tightly defined urban sections was, however, a common feature of accessibility intervention plans.

Still, the municipal authorities of Porto were committed to embedding innovation into these actions. Inspiration came from the System of Collective Spaces (SEC), which is part of the city's municipal urban development plan. It integrates all existing or planned areas, which provide appropriate levels of public enjoyment, such as major streets, squares, and green spaces. As such, the SEC would structure the liveable city, ensuring routes and elements of continuity, ordering relations between buildings, monuments, and roads, and recreating the particularities of its different parts to seize the city as a whole. The SEC was, as a result, understood as the prime vehicle to overcome the limitations of accessibility intervention plans. It created opportunities for acting upon a set of predefined and logically structured routes, rather than promoting piecemeal interventions.

The central objective of this new accessibility instrument was grounded in the definition of an agile network for the use of the urban environment, accessible to any citizen, ensuring a "right to the city" regardless of their physical capabilities. This was the foundation of the SIA, or System of Accessible Itineraries ("Sistema de Itinerários Acessíveis", in Portuguese), developed by the municipality of Porto.

According to Portuguese legislation, the network of accessible paths must be continuous and consistent, cover the entire urbanized area, and function in coordination with urban functions and activities pertaining both to public and private sectors [41]. This principle formed the basis for the initial configuration of the network. Intervening in $522 \mathrm{~km}$ of streets that compose the city of Porto would be unrealistic, as even the surveying and project stages would risk becoming outdated even before the intervention started. Following the main principles of the SEC, an intervention aiming to improve the role of public space as a structuring element of the urban system should follow basic network and continuity principles. Given the importance of public transport for the connection of key areas of a broader urban area, the metro system was adopted as the backbone of this strategy. Opened to the public in 2003, it connects the urban centre of Porto with its neighbouring municipalities, serving a considerable portion of both population and city services, thereby allowing the plan to acquire an inter-municipal scale. Being a product of the XXI century, Porto's metro system takes into account current accessibility standards, for physically and visually impaired people, inside its stations and vehicles. A stretch of $9.3 \mathrm{~km}$, encompassing two intersecting lines and seventeen stations, was selected for the first stage of this project. The intervention area for SIA encompassed a $500 \mathrm{~m}$ radius from each station, corresponding to a walkable distance of roughly under ten minutes. 
At the beginning of 2010, field assessments were conducted by municipality technicians with the aim of identifying the features of all direct pedestrian routes between each station and all public buildings within its coverage area. A tiered classification with three levels was adopted-full, partial, or weak accessibility — using the rules defined in the existing legislation as a benchmark (Table 1). This division was also represented by a three-colour scale to facilitate the interpretation of the results (Figure 1). The final classification of each section's accessibility conditions always relied on the worst performing factor. This meant that, for example, a path with sufficient width (above $2.2 \mathrm{~m}$ ) would be considered as having weak accessibility when featuring several steps. The evaluation of pedestrian crossing accessibility conditions relied mainly on its suitability for those with reduced mobility, namely, on the physical configuration of the link between sidewalk and the crossing itself. Only the absence of a formal pedestrian crossing would lead to a weak accessibility score. Figure 2 exemplifies common physical accessibility barriers found on the streets of Porto.

Table 1. Path accessibility criteria.

\begin{tabular}{|c|c|c|c|}
\hline Path Features & $\begin{array}{c}\text { Full Accessibility } \\
\text { (Green) }\end{array}$ & $\begin{array}{c}\text { Partial Accessibility } \\
\text { (Yellow) }\end{array}$ & $\begin{array}{c}\text { Weak Accessibility } \\
\text { (Red) }\end{array}$ \\
\hline Sidewalk width & $\geq 2.2 \mathrm{~m}$ & $\geq 1.2 \mathrm{~m}$ and $<2.2 \mathrm{~m}$ & $<1.2 \mathrm{~m}$ \\
\hline Sidewalk upkeep & Good & $\begin{array}{c}\text { Moderate signs of } \\
\text { degradation }\end{array}$ & $\begin{array}{l}\text { Major signs of } \\
\text { degradation }\end{array}$ \\
\hline Level difference & Inexistent & Single step & Several steps \\
\hline Extension (m) & 35.297 & 7.774 & 6.893 \\
\hline Pedestrian crossing & Ramp & Single step & Inexistent \\
\hline Extension (m) & 2.898 & 875 & 0 \\
\hline
\end{tabular}

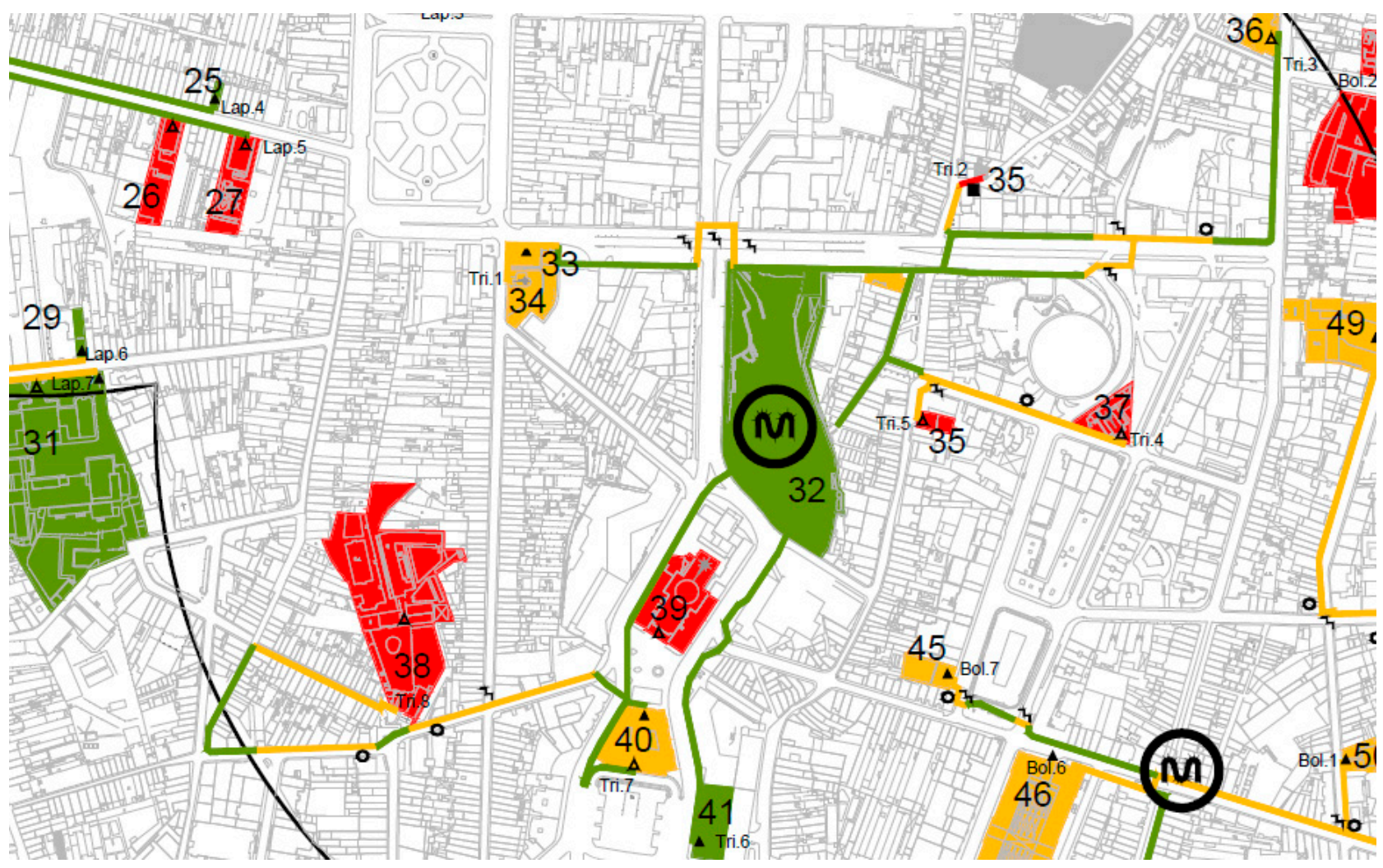

Figure 1. Sample from the physical survey data collection. 


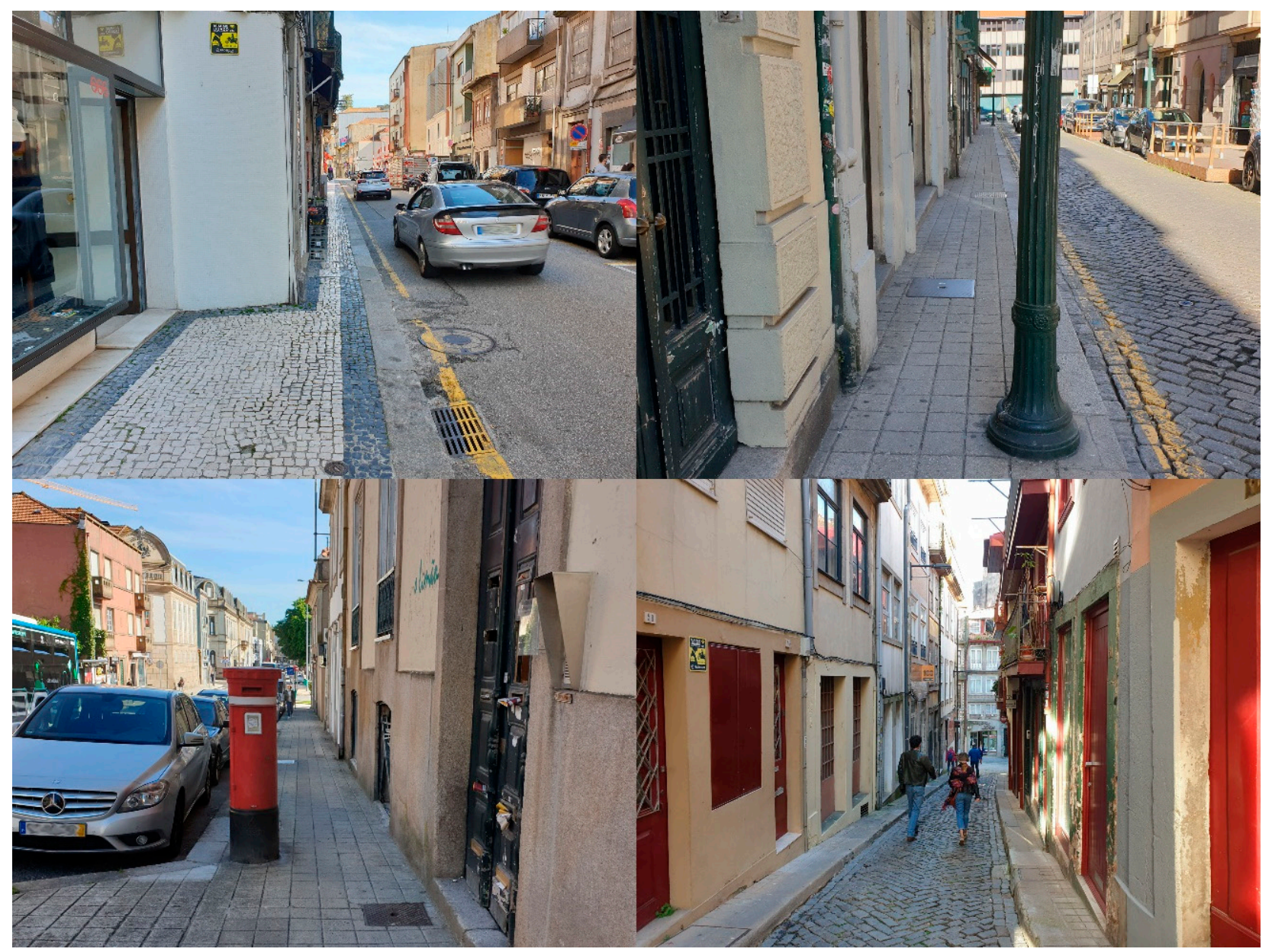

Figure 2. Typical urban design barriers found on the streets of Porto.

The assessment process resulted in the evaluation of a total of $50 \mathrm{~km}$ of paths, of which roughly $70 \%$ provided full accessibility. In addition, it encompassed $4 \mathrm{~km}$ of pedestrian crossing, of which 76\% were coloured green on the assessment maps. A slope analysis-an element of the utmost importance for wheelchair users but also practical for other groups with locomotion difficulties, such as the elderly_-was part of the route assessment during the pilot stage, but absent from the final version of the SIA.

The building evaluation chart comprised the physical accessibility features of the entrance to the building, floor connections, public toilets, and car parking, if available at the site (Table 2). The final scoring criteria followed the same rules as those for pedestrian paths. The results demonstrate that most public buildings fail in the provision of proper accessibility conditions.

Table 2. Building accessibility criteria.

\begin{tabular}{|c|c|c|c|}
\hline Building Features & $\begin{array}{c}\text { Full Accessibility } \\
\text { (Green) }\end{array}$ & $\begin{array}{c}\text { Partial Accessibility } \\
\text { (Yellow) }\end{array}$ & $\begin{array}{c}\text { Weak Accessibility } \\
\text { (Red) }\end{array}$ \\
\hline $\begin{array}{c}\text { Entrance } \\
\text { Floor connection } \\
\text { Public toilets } \\
\text { Car parking * }\end{array}$ & Level surface, ramp, or elevator & Single step & Several steps \\
\hline Total buildings & 24 & 65 & 75 \\
\hline
\end{tabular}


In 2013, the System of Accessible Itineraries was presented as an online platform [67], making use of four key components:

- Sidewalk accessibility conditions;

- Route calculation;

- Public building conditions;

- Public events.

Resulting from the surveying process, route calculation became the showcase feature of SIA. Starting with user defined origin and destination points, within the limits of the surveyed area, SIA was designed to provide route guidance, while detailing accessibility conditions for each step of the trip (Figure 3). This route calculation procedure was also characterized by using the metro system as a backbone for longer travel distances.

This feature of the SIA combines existing approaches on interactive accessibility route calculations that predict which physical obstacles might appear, such as MAGUS, U-Access and mPASS [43-45], with the online nature of other well-known tools such as Google Maps, which solely calculate the shortest route between two points.

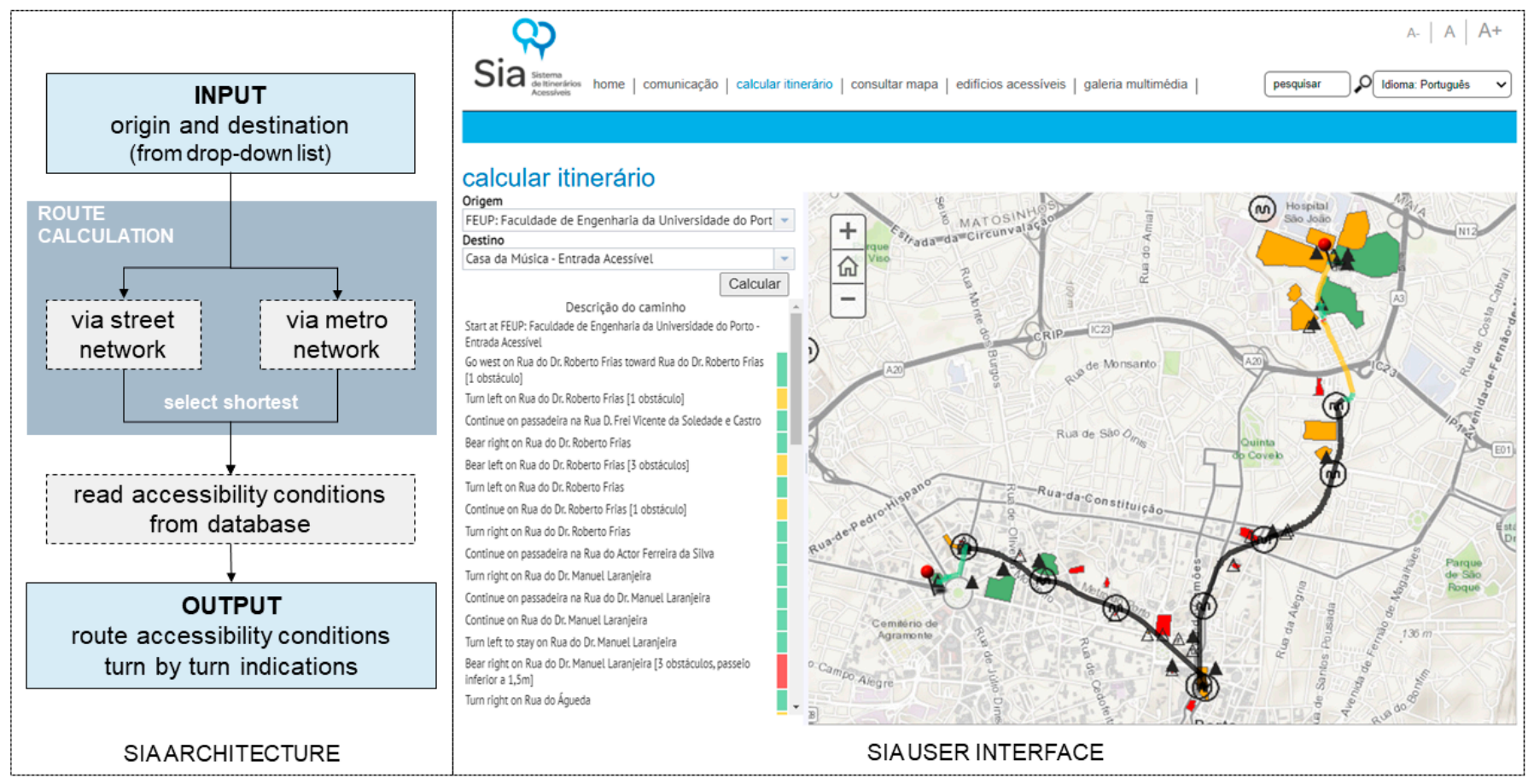

Figure 3. Architecture of the route calculation process of the SIA and its user interface. Source: CMP, 2013.

\section{Analysis of the System of Accessible Itineraries}

For a clear systematization, the following analysis is structured according to three components—urban, social, and operational ones.

\subsection{Urban Component}

The polycentric structure of the city of Porto, in line with the nature of its wider metropolitan area, is responsible for a wide dispersion of facilities and activities. An unarticulated assessment process, i.e., attempting to link all public buildings within a certain area of the city, would undeniably lead to a lengthier assessment procedure, but would also most likely fail to follow criteria of efficiency. Therefore, verifying the effectiveness of the approach adopted in the development of SIA requires, first and foremost, an assessment of the number of public facilities covered by the network. Representing $20 \%$ of the municipality area, the intervention area ideally should present an equipment coverage rate 
above this value to be considered adequate (Figure 4). Facilities were divided into four main groups (Table 3 ).

Table 3. Groups and corresponding public facilities.

\begin{tabular}{lc}
\hline Groups & Facilities \\
\hline Education & Kindergartens, schools, colleges and higher education institutions \\
Health & Hospitals, health centres, treatment, and diagnosis centres \\
Culture and Leisure & Museums, theatres, libraries, public markets, and churches \\
Public services & City hall, parish headquarters, courthouses, notaries, tax offices and post offices \\
Administration & Representations and delegations of state services, municipal utilities headquarters \\
\hline
\end{tabular}

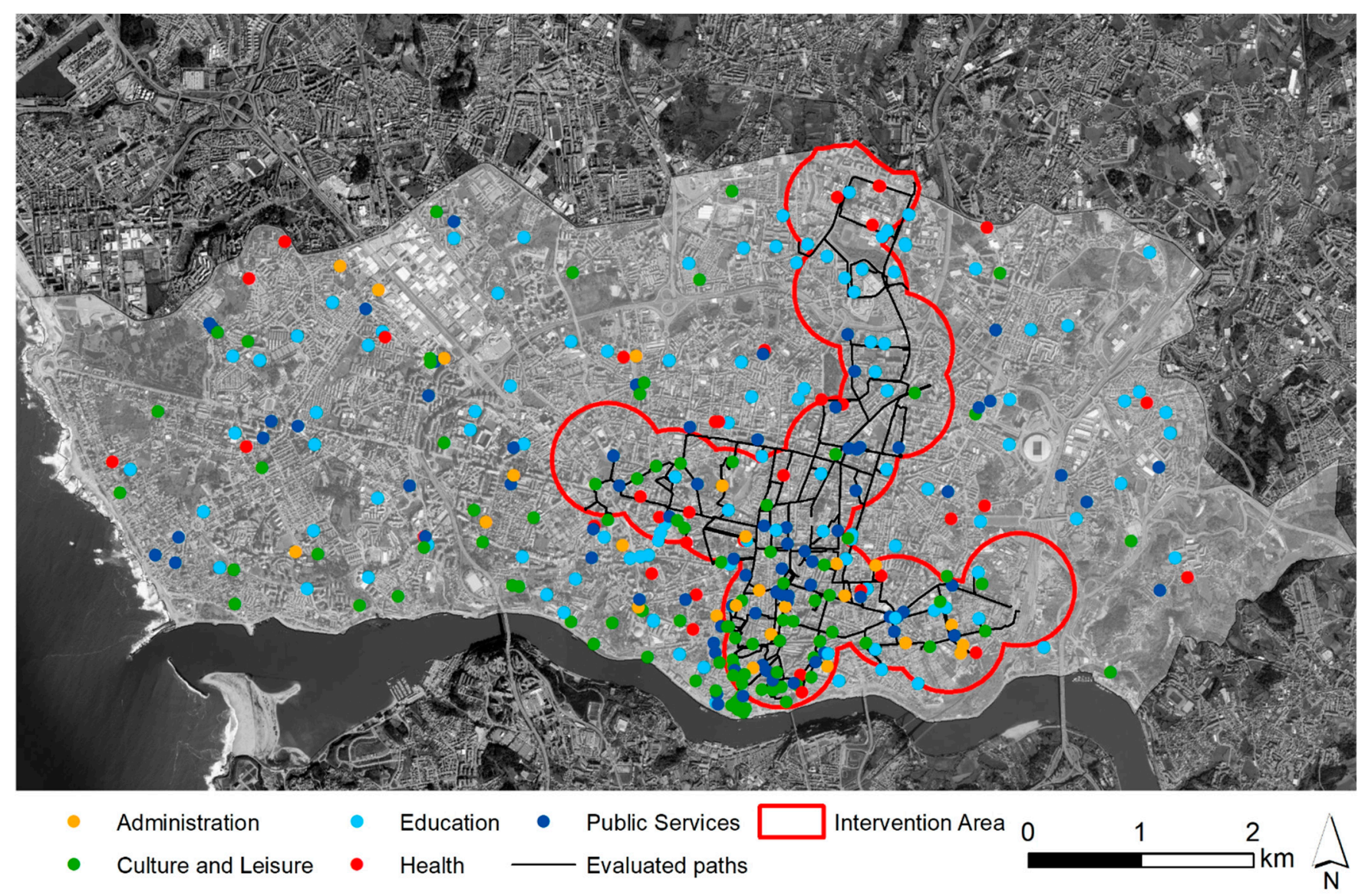

Figure 4. Coverage area of the system of accessible itineraries.

This analysis demonstrates that the chosen strategy was a good option in terms of public facility coverage (Table 4). In all categories, the coverage rate is above the municipality average, with a stronger differential in the "culture and leisure", "public services" and "administration" sectors. This outcome is, nonetheless, expected due to the comprehensive inclusion of Porto's central area, home to some of most important public facilities of the city, such as theatres, courthouses, and most of the municipal services. Education is the category with the lowest coverage rate, due to its relatively homogeneous territorial distribution. Even so, this analysis revealed a coverage rate of 30\% (24\% when considering solely the students included in the public schooling system, from 5 to 18 years of age). 
Table 4. Coverage of public facilities within the SIA intervention area.

\begin{tabular}{|c|c|c|c|c|c|}
\hline & \multicolumn{2}{|c|}{ Porto } & \multicolumn{3}{|c|}{ SIA Intervention Area } \\
\hline & Facilities & $\begin{array}{c}\text { Density } \\
\left(\text { Facilities } / \mathbf{k m}^{2} \text { ) }\right.\end{array}$ & Facilities & $\begin{array}{c}\text { Density } \\
\left(\text { Facilities } / \mathrm{km}^{2}\right)\end{array}$ & $\%$ of Porto's Total \\
\hline Education & 110 & 2.7 & 32 & 3.8 & 30 \\
\hline Health & 36 & 0.9 & 16 & 1.8 & 44 \\
\hline $\begin{array}{l}\text { Culture and } \\
\text { Leisure }\end{array}$ & 94 & 2.3 & 45 & 10.8 & 48 \\
\hline Public Services & 81 & 2.0 & 43 & 4.9 & 53 \\
\hline Administration & 25 & 0.6 & 15 & 1.7 & 60 \\
\hline
\end{tabular}

The focus of SIA on accessibility to public buildings, with the metro stations of Porto as a starting point, was used as a premise to increase the efficacy of the initial surveying process. Nevertheless, this also means that the vast majority of pedestrian paths are absent in the analysis, which reduces the relevance of an assessment based on population coverage, as it is not possible to gauge the accessibility conditions surrounding each residential building. Still, nearly 220,000 residents in the entire metropolitan area live within a $500 \mathrm{~m}$ radius of the 82 metro stations. These potential users can benefit, at least in the last stage of their trips (i.e., after leaving the metro system) from the information provided in this assessment process.

\subsection{Social Component}

In a wider social perspective, merits can be attributed to the SIA in its attempt to define and treat the structure of the system of collective spaces as a new backbone of the broader urban experience. Guaranteeing elements of continuity, ordering links between streets, facilities and monuments, while exploring them through an accessibility perspective, has the potential to recreate urban identities and as such reinforce quality of life.

However, one also must look to the inner workings of the development process of this tool. In this regard, the involvement of organized civil society, under its various forms, constitutes one of the most important forms of information and feedback collection to the planning process. Conversely, the daily discrimination to which the target groups of this project are subject jeopardize their citizenship rights. As associations can be essential intermediary agents in the transformation of the urban environment, the municipality of Porto created the figure of Municipal Ombudsman for Citizens with Disabilities, aiming to establish a more direct line of communication between the administrators and local associations. The Ombudsman served as a key vessel for the promotion of the SIA. However, the position was extinguished in 2018, absorbed by the broader Inclusion Office in the midst of heated political debate; thus far, no plans have been put in place to restore the previous strategy.

During the development of the SIA, it was broadly acknowledged that a solid dissemination plan was determinant for the involvement of the broader civil society. Although this plan anticipated several awareness-raising meetings, regular newsletters, TV spot airings, and the dissemination through the daily press, the vast majority of planned measures was not implemented, weakening the potential of the instrument to foster change. In addition, the fourth component of the SIA-informing the population of public events and activities and confronting this information with the physical accessibility of buildings-was not included in the online platform, undermining the full potential of the social component.

It is important to underline that this communicative dimension of SIA was targeted to the local population, justifying the absence of a dedicated mobile app and the nonfunctional statues of its English version pages. The absence of a topography analysis feature in the route creation tool is another key deterrent to a stronger social outreach, particularly to wheelchair users and otherwise mobility impaired people. In fact, a substantial portion of routes were identified as fully accessible within the central area of the city features steep slopes (over 6\%), hence they are actually inaccessible to many of these users. The decision 
to not include this feature was justified by the municipality for the difficulty in eliminating such barriers. The most pressing obstacles were the high cost of creating a widespread system of mechanical means such as escalators and elevators, and strict regulations in some sections of the city classified as UNESCO heritage sites. Even so, the municipality has been attempting to minimize the impact of some of the major topographic barriers in the limit of its heritage zone, as will be seen further in this paper.

\subsection{Operational Component}

The relatively strong broadband internet penetration in Portugal, covering $56 \%$ of all households [68], highlighted digital platforms as an excellent medium to boost the reach of an accessibility-led instrument. Providing detailed information on the physical accessibility features of public space through a traditional support, such as paper, would incur higher material expenditure, as new material would have to be produced whenever any change took place. In fact, this innovative technological component was the main justification for the SIA to receive the Svayam Accessibility Award 2015, in the category of "Best Practice by a Municipality", as well as a national Access to Culture award in 2017, under the category "Physical Accessibility".

The nature of the digital network ensures that, under properly designed update schemes, information remains current and up to date. However, an in-depth assessment of the online database reveals a series of inconsistencies. While some accessibility barriers have since been corrected and are not displayed on the online platform, some public facilities have been relocated or even closed to the public. The effort that was dedicated to its creation and implementation appears to have been faded by time and subsequent changing political forces. As mentioned earlier, the inoperative status of SIA's English version page is another negative aspect on the analysis of its operational component. This comes as one of the drawbacks of adopting a digital platform. Without a steady and strong commitment by its owner, some of its intrinsic value can, indeed, be lost.

\subsection{Discussion of the Role of SIA}

The discussion of the contribution of the System of Accessible Itineraries (SIA) can assume two distinct angles, the first related to the improvement of the tool itself, and the second focused on the exploration of future synergies to improve its contribution to society and to enhancement of the urban landscape.

Regarding the first branch of analysis, an introductory note on the use of the public transport system as the structuring element of SIA is crucial. As the Porto metro system spills over the administrative boundaries of the municipality of Porto, there is a strong potential for replication to neighbouring municipalities. This is extremely relevant in the context of a polycentric metropolitan region, where inter-municipality trips are commonplace in either work, study, or leisure trips.

Even within the municipality of Porto, the physical extension of the survey area to include additional metro stations or major bus routes, and thus the inclusion in the SIA platform of the pedestrian routes to nearby public buildings, constitutes a natural next step for improvement. At the same time, it is recognized that private facilities (private schools, pharmacies and supermarkets) provide important services to the communityoften comparable to public services-and should not be ignored. These two paths point to a possible reinforcement of the benefits of the SIA without distorting its key premises.

However, it is strongly advised that the SIA receives frequent updates on the physical conditions of the territory (streets and buildings) to ensure its relevance. This leads to the exploration of another improvement path. At the time of its development, in 2013, the mobile app ecosystem was not as developed as it is today, which explains the website-only nature of the SIA. Given the current widespread penetration of smartphones, the municipality should channel efforts towards the creation of a mobile app version of SIA, which would extend its reach even further, while at the time, an evaluation by municipality technicians was the only possible route to accurately survey the territory, 
today crowdsourcing methods are often used to keep online databases up to date. This is a known feature of apps such as Google Maps or Waze.

Additionally, the inclusion of the display of existing accessibility levels to the needs of different user groups is recommended. A slope analysis feature, in particular, is of crucial importance to those with limited mobility. Another important aspect is the addition of travel times, currently absent from the trip generator platform, which can be a decisive factor for a user to opt for a particular trip.

Moving to the second line of analysis, the SIA has a key role in supporting municipal technicians in the identification and prioritization of corrective actions pertaining to the public space, i.e., in removing the red and yellow portions of the surveyed routes. In early 2021, a reassessment procedure, undertaken by the authors, showed a positive contribution towards the improvement of the accessibility conditions of the public space of Porto (Table 5). Additionally, a multi-year municipality-led strategy of small scale public space improvement interventions led to a considerable improvement in previously partially accessible extensions of SIA routes $(-23 \%)$. An even more visible effort can be seen through the assessment of pedestrian crossings, with an overall increase of $15 \%$ on those providing full accessibility.

Table 5. Path accessibility re-evaluation.

\begin{tabular}{lcccccc}
\hline & \multicolumn{2}{c}{ Full Accessibility } & \multicolumn{2}{c}{ Partial Accessibility } & \multicolumn{2}{c}{ Low Accessibility } \\
\hline & $\begin{array}{c}\text { Extension } \\
(\mathbf{m})\end{array}$ & $\begin{array}{c}\text { Variation } \\
\mathbf{( \% )}\end{array}$ & $\begin{array}{c}\text { Extension } \\
(\mathbf{m})\end{array}$ & $\begin{array}{c}\text { Variation } \\
\mathbf{( \% )}\end{array}$ & $\begin{array}{c}\text { Extension } \\
(\mathbf{m})\end{array}$ & $\begin{array}{c}\text { Variation } \\
\mathbf{( \% )}\end{array}$ \\
\hline Path & 37.821 & +7 & 5.981 & -23 & 6.161 & -11 \\
Crossing & 3.345 & +15 & 428 & -52 & 0 & 0 \\
\hline
\end{tabular}

These efforts pose an undeniable contribution to concerns over the human scale of cities, linking the improvement of walkability conditions and the need to increase the liveability of public spaces. Such actions can be crucial to the revitalization of certain urban areas, through the creation of new ownership routines and social capital reinforcement. Given the nature of the SIA of connecting some of the major attractions of the city, important synergies can be boosted if linked with accessible tourism strategies [69,70]. As the implementation of differentiated services tends to, indirectly, favour discrimination, accessible tourism defends a fuller integration of actions and services, to which the information provided by SIA online database can be crucial. From the point of view of accessibility, old historic centres, such as Porto, can be easily criticized, due to the low quality standards of some narrow streets, the inadequate pavements and the existence of stairs and steps. The financial crisis of 2008 had a strong impact in public budgets and on the efforts initially launched by several municipalities. Still, in this city, the municipality has shown a recent, and strong, commitment in solving the most pressing issues related to irregular topography of its historic centre, with the meticulous installation of mechanic features (escalators) at some of its steepest areas (Figure 5).

However, when facing complex built environment barriers, universal solutions can fail to succeed, and therein lies a fundamental issue of this topic. Continuing a logic of innovation, initial studies have already been developed [71] aiming at the creation of new approaches, centred on tackling the challenges of reduced mobility when pedestrians are faced with steep slopes, and on providing more accurate means of orientation to visually impaired people. The results highlighted the existence of innovative technological solutions with potential applications in this regard and explain the feasibility of developing costeffective solutions tailored to these needs. However, additional studies and testing are needed before integration in the plan is achieved and their use is implemented.

In summary, the SIA is an important contribution to the current panorama of inclusive design approaches. It combines the assessment of features often found on walkability assessment studies [8,22], which often address urban design aspects such as the physical 
quality of pedestrian routes, to a coherent, and interactive route creation logic. The aim of connecting, efficiently, the largest number of public buildings and facilities that serve the needs of all citizens, whilst informing planning authorities on where to intervene first, reinforces its urban, social, and operational components.

While this online platform was, undeniably, a successful outcome of this strategy, its operational inefficiencies question its future viability. The municipality of Porto must first channel efforts towards updating the route and building database. Only then it can follow one of the several possible improvement paths.

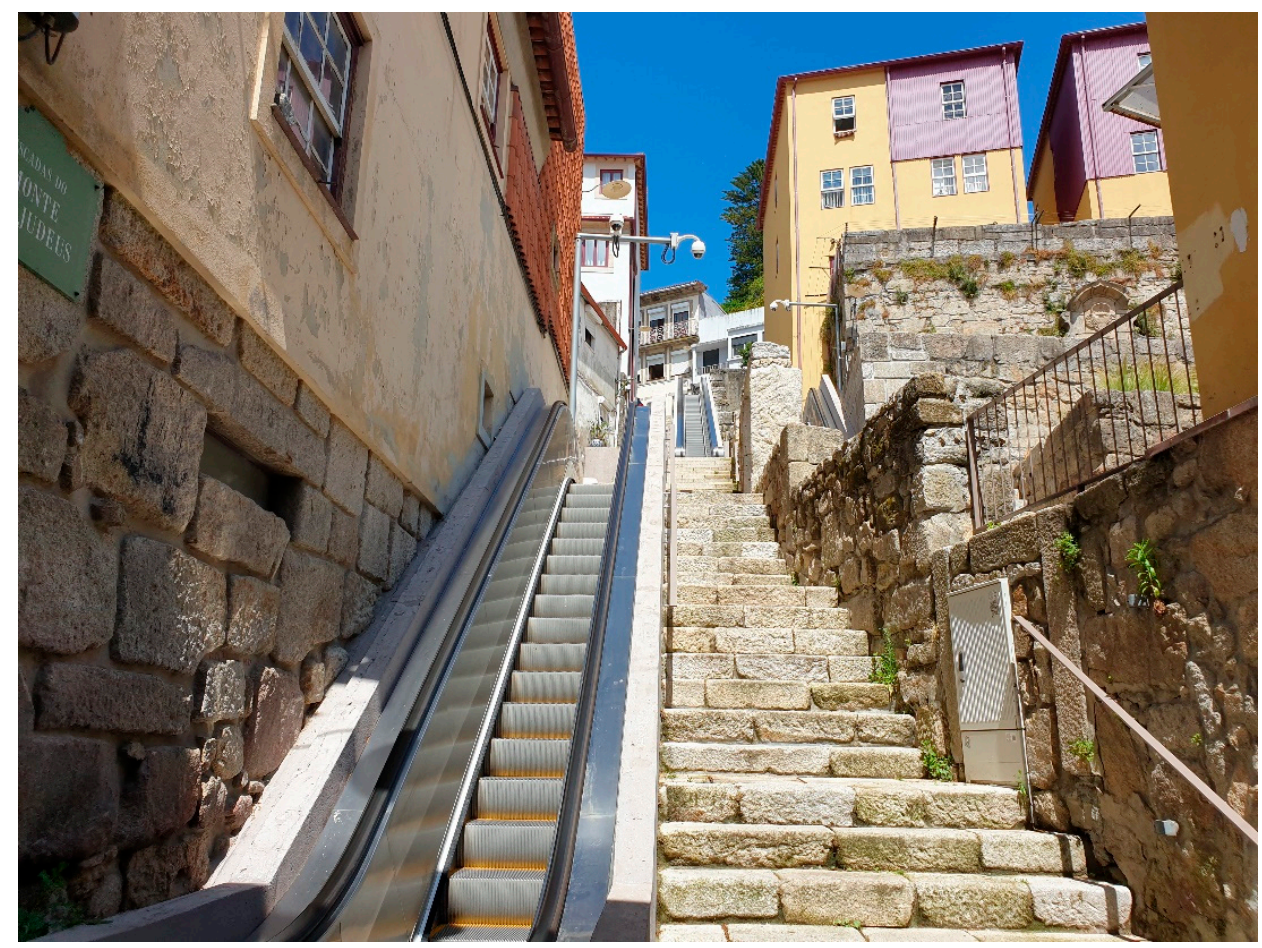

Figure 5. Recently installed escalators at Porto's historic centre.

\section{Conclusions}

Although pedestrian mobility remains essential to the basic needs of urban travel, the physical configuration of the urban environment requires special attention, as various barriers remain. These have a great impact on the daily life of those with physical limitations, namely, disabled people and the elderly, affecting their ability to freely transverse the city and to fully exercise their right to citizenship. In this sense, efforts for the promotion of accessibility are fundamental to the transformation and revitalization of public spaces, the removal of barriers, and the creation of mechanisms to prevent the perpetuation of discriminatory public spaces.

While legislation was designed to stop the proliferation of poorly designed projects, the existing system of public spaces and buildings remained immune to these efforts, unless subjected to targeted requalification schemes. For this purpose, accessibility improvement plans were designed in the Portuguese context at the intersection of traditional urban development plans and design regulations, making use of the strategic role of the planning process. However, these lacked a stronger potential for innovation.

While the scientific literature already presented numerous theoretical approaches on the evaluation of the quality and accessibility of the urban environment, its translation into practical approaches is still lacking.

The municipality of Porto saw this as an opportunity to harvest the benefits of a novel approach. The System of Accessible Itineraries was developed, at the time, under an innovative technological and contextual framework, combining inclusive accessibility, sustainable mobility, and digital accessibility. This link between universal accessibility 
and sustainable mobility ensured a strong compatibility between social, economic, and environmental sustainability. This interconnection, lying within the complexity of the urban planning process, reinforces the merit of the adopted approach, and can be considered as an important first step towards changing the existing paradigm of planning for accessibility.

Apart from the inherent advantages to citizens with reduced mobility, the SIA has the ability to inform urban planners concerning areas in need of intervention, prioritizing the execution of corrective actions within the public space. This is an aspect in which the municipality of Porto has clearly benefitted, which today features a more accessible urban environment than the one in place at the time of the creation of SIA. Due to the morphological similarity of the consolidated urban fabric of most Portuguese and European city centres, the aforementioned framework owns an enormous replication potential. The logic that followed the creation of a network of accessible routes can serve as an inspiration to other municipalities that envision a more inclusive urban environment.

In addition, it can provide contributions at the psychological and social levels, by changing the mindset of planners and other urban space creators, but also that of the "ordinary citizen". The biggest contribution of the SIA is, in fact, hidden to the eyes of the public, and is aimed at those with locomotion difficulties, enabling the full realization of their citizenship. No instrument should be seen as a "magic wand" that will automatically provide the desired accessibility on its own. The fact that the SIA platform lacks a frequent updating scheme does, indeed, penalize its true potential, something that can be improved with the use of currently available crowdsourcing techniques. Despite the positive contribution of the SIA to the "planning for accessibility" paradigm, these inefficiencies should be seen as a warning sign for municipalities that wish to embark on a similar strategy. While all levels of governance and sectors of society should elect accessibility as an ultimate objective, this requires that each of them acquires and develops the needed skills, and capacity, to successfully reach the sought-after result.

Author Contributions: Conceptualization, M.L. and F.A.; methodology, M.L.; supervision, F.A.; validation, M.L. and F.A.; formal analysis, M.L.; investigation, M.L.; visualization, M.L.; writingoriginal draft preparation, M.L.; writing —review and editing, M.L. and F.A. All authors have read and agreed to the published version of the manuscript.

Funding: This research received no external funding.

Institutional Review Board Statement: Not applicable.

Informed Consent Statement: Not applicable.

Data Availability Statement: All databases used in this paper were built from the publicly available information on the SIA webpage.

Acknowledgments: The authors would like to thank the Urban Planning Department of the Municipality of Porto, and especially Architect João Palha de Araújo Pestana, who provided key information for the development of this research.

Conflicts of Interest: The authors declare no conflict of interest.

\section{References}

1. Cruz, N.; Rode, P.; McQuarrie, M. New urban governance: A review of current themes and future priorities. J. Urban Aff. 2019, 41, 1-19. [CrossRef]

2. Lowe, T. New development: The paradox of outcomes-The more we measure the less we understand. Public Money Manag. 2013, 33, 213-216. [CrossRef]

3. Brain, D. Democracy and Urban Design: The Transect as Civic Renewal. Places 2006, 18, 18.

4. Mossberger, K.; Stoker, G. The evolution of urban regime theory the challenge of conceptualization. Urban Aff. Rev. 2001, 36, 810-835. [CrossRef]

5. Bentley, I.; Alcock, A.; Murrain, P. Responsive Environments: A Manual for Designers; Architectural Press: Oxford, UK, 1985.

6. Lavery, I.; Davey, S.; Woodside, A.; Ewart, K. The vital role of street design and management in reducing barriers to older peoples' mobility. Landsc. Urban Plan. 1996, 35, 181-192. [CrossRef] 
7. Mora, H.; Gilart-Iglesias, V.; Pérez del Hoyo, R.; Andújar-Montoya, M. A Comprehensive System for Monitoring Urban Accessibility in Smart Cities. Sensors 2017, 17, 1834. [CrossRef]

8. Alves, F.B.; Cruz, S.; Ribeiro, A.; Bastos Silva, A.M.C.; Cunha, I.; Martins, J. Walkability Index for Elderly Health: A Proposal. Sustainability 2020, 12, 7360. [CrossRef]

9. Titheridge, H.; Mackett, R.; Achuthan, K. From footway design to the street environment: Removing the barriers to walking. In Proceedings of the 10th International Conference on Walking and Liveable Communities, New York, NY, USA, 6-9 October 2009.

10. European Commission. 2010: A Europe Accessible For All. Report from Expert Group Set Up by European Commission; European Commission: Brussels, Belgium, 2003.

11. European Commission. How Many People Can You Reach by Public Transport, Bicycle or on Foot in European Cities? Measuring Urban Accessibility for Low-Carbon Modes; WP 01/2020, Regional and Urban Policies. Luxembourg; Publications Office of the European Union: Luxembourg, 2020; ISBN 978-92-76-10253-3.

12. Levine, J. A century of evolution of the accessibility concept. Transp. Res. Part D Transp. Environ. 2020, 83, 102309. [CrossRef]

13. Pérez-Delhoyo, R.; García-Mayor, C.; Mora, H.; Gilart-Iglesias, V.; Andújar-Montoya, M. Improving urban accessibility: A methodology for urban dynamics analysis in smart, sustainable and inclusive cities. Int. J. Sustain. Dev. Plan. 2017, 12, 357-367. [CrossRef]

14. Alves, F.; Ramalho, A. Principles for the Implementation of a Pedestrian Plan in Medium Size Cities. Urban Reg. Dev. Stud. 2011, 23, 21-47. [CrossRef]

15. Imrie, R.; Hall, P. Inclusive Design: Designing and Developing Accessible Environments; Spon Press: London, UK; New York, NY, USA, 2001.

16. Handy, S. Urban form and pedestrian choices: Study of Austin neighborhoods. Transp. Res. Rec. 1996, 1552, 135-144. [CrossRef]

17. Southworth, M. Designing the walkable city. J. Urban Plan. Dev. 2005, 131, 246-257. [CrossRef]

18. Newman, P.; Kenworthy, J. The land use-transport connection-An overview. Land Use Policy 1996, 13, 1-22. [CrossRef]

19. Agrawal, A.; Schlossberg, M.; Irvin, K. How Far, by Which Route and Why? A Spatial Analysis of Pedestrian Preference. J. Urban Des. 2008, 13, 81-98. [CrossRef]

20. Ferreira, A.; Batey, P.; Te Brömmelstroet, M.; Bertolini, L. Beyond the dilema of mobility: Exploring new ways of matching intelectual and physical mobility. Environ. Plan. A 2012, 44, 688-704. [CrossRef]

21. Cervero, R.; Kockelman, K. Travel Demand and the 3Ds: Density, Diversity and Design. Transp. Res. Part D 1997, 2, 199-219. [CrossRef]

22. Ewing, R.; Handy, S. Measuring the Unmeasurable: Urban Design Qualities Related to Walkability. J. Urban Des. 2009, 14, 65-84. [CrossRef]

23. Madanipour, A. Public and Private Spaces of the City; Routledge: London, UK, 2003.

24. Urry, J. The system of automobility. Theory Cult. Soc. 2004, 21, 25-39. [CrossRef]

25. Lawton, M. Social ecology and the health of older people. Am. J. Public Health 1974, 64, 257-260. [CrossRef]

26. Goldsmith, S. Designing for the Disabled: The New Paradigm; Architectural Press: Oxford, UK, 1997.

27. Imrie, R. Disability and the City: International Perspectives; Paul Chapman Publishing: London, UK, 1996.

28. Hanson, J. The Inclusive City: Delivering a more accessible urban environment through inclusive design. In Proceedings of the Conference: RICS Cobra 2004 International Construction Conference: Responding to Change, York, UK, 7-8 September 2004.

29. Townsend, P. Poverty in the United Kingdom; University of California Press: Berkeley, CA, USA; Los Angeles, CA, USA, 1979.

30. Barnes, C.; Mercer, G.; Shakespeare, T. Exploring Disability: A Sociological Introduction; Polity Press: Oxford, UK, 1999.

31. Imrie, R.; Wells, P. Disablism, Planning, and the Built Environment. Environ. Plan. C 1993, 11, 213-231. [CrossRef]

32. Burton, E.; Mitchell, L. Inclusive Urban Design: Streets for Life; Architectural Press: Oxford, UK, 2006.

33. Bertolini, L.; le Clercq, F.; Kapoen, L. Sustainable accessibility: A conceptual framework to integrate transport and land use plan-making. Two test-applications in the Netherlands and a reflection on the way forward. Transp. Policy 2005, 12, 207-220. [CrossRef]

34. Faludi, A. Planning Theory; Pergamon Press: Oxford, UK, 1973.

35. Needham, B.; Hartmann, T. Planning By Law and Property Rights Reconsidered; Routledge: London, UK; New York, NY, USA, 2016; ISBN 978-1-4094-3721-5.

36. Tennøy, A.; Hansson, L.; Liassandrello, E.; Næss, P. How planners' use and non-use of expert knowledge affect the goal achievement potential of plans: Experiences from strategic land-use and transport planning processes in three Scandinavian cities. Prog. Plann. 1979, 109, 1-32. [CrossRef]

37. Allmendinger, P. Planning Theory; Palgrave: Basingstoke, UK, 2002.

38. Taylor, N. Urban Planning Theory since 1945; Sage: London, UK, 2004.

39. NSI A117.1. Standard for Accessible and Usable Buildings and Facilities; International Code Council: Washington, DC, USA, 2009; ISBN 978-158001-918-7.

40. Council of Europe. Resolution ResAP(2001)1 on the Introduction of the Principles of Universal Design into the Curricula of all Occupations Working on the Built Environment; Adopted by the Committee of Ministers on 15 February 2001; Council of Europe: Brussels, Belgium, 2001.

41. Diário da República. Decreto-Lei n.o 123/97. I SÉRIE-A N.o 118-22-5-1997; Portuguese Republic: Lisbon, Portugal, 1997; pp. 2540-2544. 
42. Portuguese Republic. Plano Nacional de Promoção de Acessibilidade, Resolução do Conselho de Ministros 9/2007; Portuguese Republic: Lisbon, Portugal, 2007.

43. Matthews, H.; Beale, L.; Picton, P.; Briggs, D. Modelling Access with GIS in Urban Systems (MAGUS): Capturing the Experiences of Wheelchair Users. Area 2003, 35, 34-45. [CrossRef]

44. Mirri, S.; Prandi, C.; Salomoni, P. Personalizing Pedestrian Accessible way-finding with mPASS. In Proceedings of the 2016 13th IEEE Annual Consumer Communications \& Networking Conference (CCNC), Las Vegas, NV, USA, 9-12 January 2016.

45. Sobek, A.; Miller, H. U-Access: A web-baed system for routing pedestrians of differing abilities. J. Geogr. Syst. 2006, 8, 269-287. [CrossRef]

46. Curl, A.; Nelson, J.D.; Anable, J. Does accessibility planning address what matters? A review of current practice and practitioner perspectives. Res. Transp. Bus. Manag. 2011, 2, 3-11. [CrossRef]

47. Handy, S. Planning for Accessibility: In Theory and in Practice. In Access to Destinations; Levinson, D.M., Krizek, K.J., Eds.; Emerald Publishing: Bingley, UK, 2005; pp. 131-147.

48. Carr, S.; Francis, M.; Rivlin, L.; Stone, A. Public Space; Cambridge University Press: Cambridge, UK, 1992.

49. Pendlebury, J.; Short, M.; While, A. Urban World Heritage Sites and the problem of authenticity. Cities 2009, 26, 349-358. [CrossRef]

50. Wang, X.; Aoki, N. Paradox between neoliberal urban redevelopment, heritage conservation, and community needs: Case study of a historic neighbourhood in Tianjin, China. Cities 2019, 85, 156-169. [CrossRef]

51. Domaradzka, A. Urban Social Movements and the Right to the City: An Introduction to the Special Issue on Urban Mobilization. Voluntas 2018, 29, 607-620. [CrossRef]

52. Harvey, D. The right to the city. Int. J. Urban Reg. Res. 2003, 27, 939-941. [CrossRef]

53. Lefebvre, H. The Production of Space; Blackwell: London, UK, 1991.

54. Fainstein, S. Competitiveness, cohesion, and governance: Their implications for social justice. Int. J. Urban Reg. Res. 2004, 25, 884-888. [CrossRef]

55. Bisschops, S.; Beunen, R. A new role for citizens' initiatives: The difficulties in co-creating institutional change in urban planning. J. Environ. Plan. Manag. 2019, 62, 72-87. [CrossRef]

56. Nesti, G. Co-production for innovation: The urban living lab experience. Policy Soc. 2018, 37, 310-325. [CrossRef]

57. Puerari, E.; De Koning, J.; Von Wirth, T.; Karré, P.; Mulder, I.; Loorbach, D. Co-Creation Dynamics in Urban Living Labs. Sustainability 2018, 10, 1893. [CrossRef]

58. Davis, A.; Andrew, J. Co-creating Urban Environments to Engage Citizens in a Low-carbon Future. Procedia Eng. 2017, 180, 651-657. [CrossRef]

59. Foth, M. Participation, Co-Creation, and Public Space. J. Public Sp. 2017, 2, 21-36. [CrossRef]

60. Mulder, I. Living Labbing the Rotterdam Way: Co-Creation as an Enabler for Urban Innovation. Technol. Innov. Manag. Rev. 2012, 2, 39-43. [CrossRef]

61. Graham, S.; Marvin, S. Planning Cyber Cities? Integrating Telecommunication into Urban Planning. Town Plan. Rev. 1999, 70, 89-114. [CrossRef]

62. Balsas, C. City Centre Revitalization in Portugal: A Study of Lisbon and Porto. J. Urban Des. 2007, 12, 231-259. [CrossRef]

63. Carvalho, L.; Chamusca, P.; Fernandes, J.; Pinto, J. Gentrification in Porto: Floating city users and internationally-driven urban change. Urban Geogr. 2019, 40, 565-572. [CrossRef]

64. INE. Census 2011—Final Results; Instituto Nacional de Estatística: Lisbon, Portugal, 2012.

65. Aguiar, B.; Macário, R. The need for an Elderly centred mobility policy. Transp. Res. Procedia 2017, 25, 4355-4369. [CrossRef]

66. WHO. Global Age-Friendly Cities: A Guide; World Health Organization: Geneva, Switzerland, 2007.

67. CMP System of Accessible Itineraries. Available online: http://sia.cm-porto.pt/en/Pages/default.aspx (accessed on 1 March 2021).

68. INE. Fixed Broadband Internet Accesses (No.) by Geographic Localization (NUTS-2013) and Access Segment. Available online: https://ine.pt/xportal/xmain?xpid=INE\&xpgid=ine_indicadores\&indOcorrCod=0008450\&contexto=bd\&selTab=tab2 \&xlang=en (accessed on 1 March 2021).

69. Darcy, S.; Dickson, T. A Whole-of-Life Approach to Tourism: The Case for Accessible Tourism Experiences. J. Hosp. Tour. Manag. 2009, 16, 32-44. [CrossRef]

70. Altinay, Z.; Saner, T.; Bahçelerli, N.; Altinay, F. The Role of Social Media Tools: Accessible Tourism for Disabled Citizens. J. Educ. Technol. Soc. 2016, 19, 89-99.

71. Lopes, M. Plano de Promoção de Acessibilidade para Todos; Faculdade de Engenharia da Universidade do Porto: Porto, Portugal, 2005. 